\title{
ENSINO DE GEOGRAFIA FÍSICA POR MEIO DA TEMÁTICA DE RISCOS NATURAIS NO ENSINO BÁSICO
}

\author{
Camila Bento Bragança ${ }^{(a)}$, Andrezza Moreira Felizardo ${ }^{(b)}$, Anice Esteves Afonso ${ }^{(c)}$ \\ (a) Departamento de Geografia/Faculdade de Formação de Professores/Universidade do Estado do Rio de \\ Janeiro. E-mail: camila.b.03@gmail.com \\ (b) Departamento de Geografia/Faculdade de Formação de Professores/Universidade do Estado do Rio de \\ Janeiro. E-mail: andrezzamoreirafelizardo@gmail.com \\ (c) Departamento de Geografia/Faculdade de Formação de Professores/Universidade do Estado do Rio de \\ Janeiro. E-mail: aniceuerj@gmail.com
}

\section{EIXO: GEOGRAFIA FÍSICA: CURRÍCULO, FORMAÇÃO E PRÁTICA DE ENSINO}

\begin{abstract}
Resumo
A disciplina de Geografia física no ensino básico é importante na compreensão dos fatores físicosambientais contribuindo assim no entendimento da dinâmica da natureza e também para compreender as situações de riscos naturais, aproveitar os conhecimentos cotidianos dos alunos pode ser uma estratégia eficiente para estimular a aprendizagem significativa desses conteúdos, de forma que ele possa correlacionar estas temáticas segundo a sua realidade de vida. Por isso, o grupo de pesquisa "Ensino de Geografia Física e Formação de Professores" do DEGEO/FFP/UERJ a partir da metodologia proposta pela Defesa Civil da Cidade do Rio de Janeiro (DCRJ), que se constitui do mapeamento de riscos em áreas próximas as escolas com imagens do Google Earth, propôs atividades didáticas a serem feitas em sala de aula que pudesse não só expor o conteúdo referente à dinâmica geomorfológica mais também envolver atividades lúdicas que ajudassem os alunos a desenvolverem a sua percepção de risco.
\end{abstract}

Palavras chaves: Ensino de Geografia Física, Ensino Básico, Riscos Naturais e Mapeamento de Risco.

\section{Introdução}

Nos últimos anos tem aumentado o debate sobre a temática de riscos naturais devido aos eventos naturais extremos que ocorreram na cidade do Rio de Janeiro e na sua Região Metropolitana e Serrana gerando vários prejuízos econômicos, materiais e sociais. Portanto, houve a necessidade de ampliar a discussão em relação à questão ambiental e de risco de forma que pudesse ser disseminado para a sociedade em geral as informações de prevenção e/ou mitigação dos eventos naturais extremos de forma eficiente.

"Sabe-se que os eventos naturais como os deslizamentos e inundações fazem parte da dinâmica da natureza e são processos constantes na história do nosso planeta" (CEPED/UFSC, 2012). Contudo, com o processo de urbanização principalmente em áreas ambientalmente vulneráveis tem aumentado o número de pessoas em situações de risco iminente e por isso percebeu-se a importância da conscientização e da cultura de percepção de risco como uma alternativa positiva de minimizar os efeitos dos eventos naturais na vida dessas pessoas levando como ponto de partida o entendimento sobre o local onde se habita. 
A lei 12.608 de 2012 estabeleceu a Política Nacional de Proteção e Defesa Civil que ajudou a ampliar a divulgação das noções de redução da vulnerabilidade e risco de desastre. Sendo assim, ela em seu artigo 29 alterou a lei 9.394 (Diretrizes e Bases da Educação Nacional) em seu parágrafo 7 passa a incluir a Educação Ambiental e os Princípios de Proteção e Defesa Civil nos conteúdos escolares obrigatórios. Por isso, acredita-se que o aprofundamento e o entendimento sobre a dinâmica da natureza utilizando conteúdos e conceitos do ensino de Geografia Física em sala de aula formam indivíduos com consciência ambiental e sustentável em prol da preservação da natureza.

Sendo a Geografia a ciência que estuda o espaço geográfico e as relações que são estabelecidas nele, pode-se incluir a relação homem e meio visto que o homem ao se relacionar com o espaço onde vive se apropria dele para constituir o seu modo de vida, logo essa relação pode gerar ações que podem potencializar os efeitos dos eventos naturais extremos. Por isso, a temática de riscos naturais juntamente com a compreensão dos fatores físicos-ambientais contribui para o entendimento da dinâmica da natureza e também para compreender as situações de riscos naturais, aproveitar os conhecimentos cotidianos dos alunos pode ser uma estratégia eficiente para estimular a aprendizagem significativa desses conteúdos, de forma que ele possa correlacionar estas temáticas segundo a sua realidade de vida. Desta forma, temáticas como essa precisam ser discutidas em sala de aula levando em consideração o cotidiano do aluno e os riscos mais frequentes ou sofridos por eles para que o ensino da educação geográfica seja mais significativo de forma a contribuir para a divulgação das informações sobre os eventos naturais e divulgar também o trabalho das instituições de proteção e defesa civil de cada município onde a escola está inserida. Portanto, este trabalho teve como objetivo ajudar a Defesa Civil da Cidade do Rio de Janeiro (DCRJ) a divulgar as noções de prevenção e mitigação de riscos naturais e de conscientização ambiental com alunos do $5^{\circ}$ e $6^{\circ}$ ano de escolas públicas tanto da Cidade do Rio de Janeiro quanto da Região Metropolitana, mais precisamente no Município de São Gonçalo a fim de tornar as crianças em cidadão mais engajados socialmente nas questões ambientais e na preservação da natureza.

\section{Materiais e Métodos}

Este trabalho consiste de um relato de experiência que foi feito por meio da parceria entre o grupo de pesquisa "Ensino de Geografia Física e Formação de Professores" do DGEO/FFP/UERJ com a Defesa Civil da Cidade do Rio de Janeiro que a partir da proposta da SUBDEC- Subsecretaria de Defesa Civil- foi criado o programa "Defesa Civil nas Escolas" (PDCE) que consiste em um conjunto de palestras que abordam a temática de riscos naturais em escolas públicas da Cidade do Rio de Janeiro com o intuito de fortalecer a política de prevenção e mitigação de riscos ambientais em áreas consideradas de grande vulnerabilidade a fim de 
contribuir para minimizar os efeitos dos eventos naturais extremos e desta forma aumentar o poder de resiliência não só dos estudantes mais de toda a comunidade ao redor da escola. Ao todo foram 38 escolas públicas que participaram deste projeto ao longo do ano de $2016 \mathrm{com}$ alunos do $5^{\circ}$ e $6^{\circ}$ ano, essa faixa etária é considerada pela instituição de proteção e defesa civil ideais para discutir a temática de risco no ensino básico.

A compreensão acerca da dinâmica da natureza dentro do ensino de geografia física tais como o de sistemas fluviais e de encosta além dos fatores que ajudam a contribuir para o aumento das situações de risco como o de lançamento de água servida (esgoto), poluição da água, do solo, urbanização desordenada, desmatamento entre outros ajudam a contribuir para minimizar os efeitos dos eventos naturais extremos em comunidades onde se situam em áreas ambientalmente vulneráveis. Segundo Afonso, (2013) é extremamente importante entender as dinâmicas naturais e como elas interagem com a sociedade a fim de compreender melhor o espaço geográfico além de promover o entendimento sobre as situações de risco.

Os docentes em geografia podem utilizar os conteúdos referentes a geografia física para desenvolver nos alunos a sua percepção de risco, utilizando os riscos naturais mais frequentes na cidade, no bairro ou até mesmo na escola onde o discente está inserido. Isto faz com que a educação geográfica se torne mais significativa e desperta nos alunos o sentimento de pertencimento do lugar o que pode contribuir para que os mesmos se tornem mais conscientes ambientalmente e se tornem cidadãos mais ativos na sociedade. Acredita-se que este tipo de abordagem o olhar sobre os aspectos naturais e culturais presente nos ambientes mudam, pois os estudantes se tornam mais críticos o que contribui também para o desenvolvimento da percepção mais aguçada e preventiva.

Os estudantes são vistos como potenciais disseminadores de informações, sendo assim a Defesa Civil elaborou um conjunto de palestras separado por quatro módulos como estratégia de aplicação dos conhecimentos sobre a temática de risco. No primeiro e segundo módulo foi abordada a importância da defesa civil na sociedade e foi discutido também os tipos de riscos naturais mais frequentes na Cidade do Rio de Janeiro e os riscos de acidentes domésticos, pois muitos estudantes da rede de ensino cuidam de irmãos pequenos ou de alguma criança na comunidade onde vivem logo a DCRJ considera importante abordar este assunto com os alunos. Os riscos mais frequentes na Cidade do Rio de Janeiro e da Região Metropolitana são: alagamento, inundação, deslizamento e queda de blocos entre outros riscos que são juntamente abordados com os conceitos considerados importantes para se compreender as situações de risco geomorfológico que são os conceitos de risco, vulnerabilidade, ameaça, instabilidade, resiliência, entre outros. Esta abordagem ajuda a desenvolver nos alunos a percepção de risco 
que se torna uma ferramenta muito eficaz para diminuir a vulnerabilidade e aumentar o poder de resiliência da comunidade e dos alunos frente aos eventos naturais que podem vir a ocorrer.

Utilizou-se como material de suporte os recursos audiovisuais e projetores de forma que pudesse auxiliar na maior compreensão dos fenômenos naturais. Por meio das palestras, pôde-se discutir sobre os riscos de deslizamentos e inundações que afetaram as populações que habitam em áreas vulneráveis utilizando imagens de desastres que ocorreram em 2010 na Região Metropolitana e em 2011 na Região Serrana e na Cidade do Rio de Janeiro no mesmo período. Com o intuito de trazer exemplos de fenômenos que ocorreram próximos a realidade dos alunos para que as informações que seriam passadas pudessem despertar neles o interesse e a sensibilização em relação aos os que sofrem diretamente com esse fenômeno podendo assim ajudar a preservar a natureza e a respeitar e conhecer o ambiente onde vivem.

Foi utilizado como atividade de fixação dos conhecimentos que foram adquiridos nas palestras $o$ "Mapeamento de Risco" utilizando imagens do Google Earth da escola e dos bairros adjacentes, de forma que os estudantes pudessem localizar e registrar no mapa os riscos mais frequentes ou situações que eles identificaram no seu lugar de vivência que poderiam ter o potencial de provocar um acidente ambiental e que poderiam coloca-los em situação de perigo. Logo, automaticamente por meio desta atividade os alunos puderam adquirir um olhar diferente sobre o espaço geográfico onde se inserem desenvolvendo assim a sua percepção de risco que lhes ajudam a identificar fenômenos ou situações que podem ter potencial de causar um dano material, econômico e social.

Para tal atividade os alunos foram dispostos em grupos onde os mesmos deveriam relatar para os seus colegas de classe os tipos de riscos que eles conseguiram identificar em sua comunidade ou em lugares ao redor da escola levando em consideração a presença de relevos, rios, blocos de rocha etc. para que no final pudessem montar o seu mapa de risco. Pôde-se perceber por meio desta atividade que os estudantes conseguiram sintetizar e absorver os conhecimentos e informações sobre a dinâmica da natureza e dos riscos decorrentes dela de maneira efetiva, logo acredita-se que os alunos passarão adiante tudo que aprenderam. Isto, converge com o objetivo geral deste trabalho e das palestras que consiste em disseminar as informações sobre noções de riscos naturais no ensino básico.

No terceiro módulo fala-se da importância do conhecimento do primeiro-socorro, esta etapa é feita pelos profissionais da Cruz Vermelha em parceria com a DCRJ e no último módulo é discutido sobre as consequências das chuvas fortes e concentradas principalmente em áreas ambientalmente vulneráveis, o sistema de alerta e alarme, pontos de apoio entre outros assuntos ligados a prevenção e mitigação de riscos encerrando o encontro com o exercício de simulado. 
OS DESAFIOS DA GEOGRAFIA FÍSICA NA FRONTEIRA DO CONHECIMENTO

Instituto de Geociências - Unicamp

Campinas - SP

28 de Junho à 02 de Julho de 2017

Os exercícios de simulado vem acompanhado de conteúdos que discutem sobre as consequências das chuvas intensas e concentradas na cidade do Rio de Janeiro e na sua Região Metropolitana que ocorrem nos meses de novembro a abril, ou seja, no verão. E que por meio das interferências humanas negativas no ambiente intensificam os efeitos dos eventos naturais podendo ocasionar em desastres. Como a ocupação desordenada, construções de baixo padrão em áreas íngremes, desmatamento, despejo de água servida (esgoto) no solo, despelo inadequado de lixo que potencializam a ocorrência de deslizamentos e inundações. O simulado como o próprio nome já diz tem o objetivo de simular quais os procedimentos que precisam ser feitos pelos moradores de áreas de risco em períodos de chuvas fortes, esse processo consiste na desocupação por meio do alerta das sirenes que são colocadas em lugares considerados de grande risco dentro das comunidades. Quando os alarmes das sirenes disparam, elas indicam possível risco de deslizamento, e os moradores se deslocaram para os pontos de apoio permanecendo lá até que as sirenes indiquem a situação de retorno à normalidade para que assim possam voltar para as suas casas. Estes exercícios são reproduzidos nas escolas onde os alunos são divididos em moradores, agentes comunitários e assistentes sociais e por meio do toque da sirene que são feitos pelos profissionais da DCRJ os alunos que na verdade se colocam como os agentes comunitários conduzem os alunos que fazem o papel de moradores para o local de apoio onde são recebidos pelos alunos que fazem o papel de assistentes sociais que darão as orientações e distribuirão panfletos para todos os moradores. O exercício de simulado mobiliza todos os alunos do $5^{\circ}$ e $6^{\circ}$ ano o que permite que alunos que não participam diretamente do projeto tenham a oportunidade de conhecer a DCRJ e participar da atividade.

Todos esses encontros são feitos em dias diferentes por meio de agendamento com a direção das escolas participantes. No final do ano letivo são feitas cerimônias de entrega de certificados para os alunos que participaram do projeto onde os mesmos passam a ser considerados pela DCRJ como agentes jovens da Defesa Civil e sendo assim passam ajuda-los a disseminar informações de prevenção de riscos naturais para toda comunidade tornando-os mais resilientes. Geralmente a cerimônias de formatura ocorrem em novembro ou dezembro.

\section{Resultados e Discussões}

Esse trabalho de voluntariado na DCRJ nos possibilitou uma nova prática de ensino a partir dessa temática, através do ensino significativo que se apropria dos elementos culturais e dos saberes tanto do senso comum quanto do meio científico, que são mediadas pelos professores de maneira a criar condições para que, o estudante reflita e pense de forma crítica sobre o modo como o espaço geográfico se comporta em relação ao convívio direto com a sociedade. Desta forma, pode-se propor uma Educação Ambiental que colabore com práticas sustentáveis de 
minimização dos efeitos dos eventos naturais extremos. Lembrando sempre a importância de termos lei que abarque a causa, respaldando assim as ações propagadas pelos educadores.

As palestras realizadas pelo grupo de pesquisa com o intuito de alcançar o que foi proposto acima, foram realizadas em Escolas Estaduais no Município de São Gonçalo, oficinas essas que foram aplicadas tanto para alunos no Ensino Médio (Colégio Estadual Nilo Peçanha) e Fundamental II (CIEP 439 Luís Gonzaga Júnior), buscando divulgar essas informações e aproximar a Universidade da Escola Básica, na perspectiva na Educação Ambiental. Segue abaixo a imagem das atividades feitas no Colégio Estadual Nilo Peçanha e no Ciep 439 Luís Gonzaga Júnior.

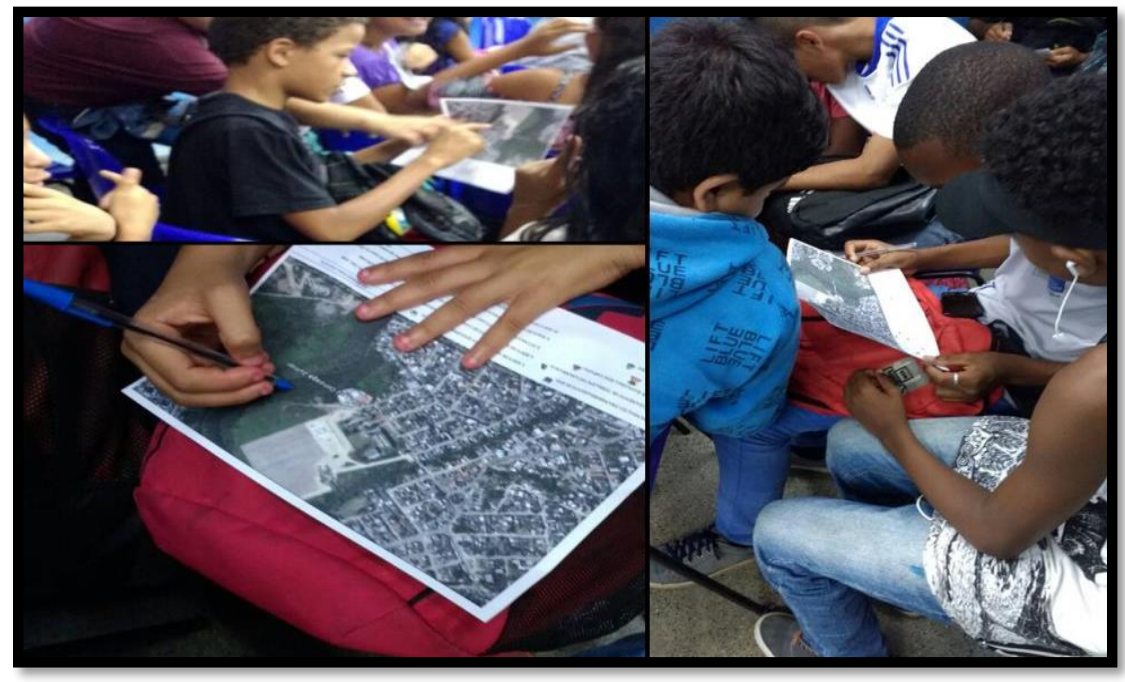

Figura 1 - Palestra realizada no CIEP 439 Luiz Gonzaga Júnior- $7^{\circ}$ ano (24/11/2016) / Alunos do $2^{\circ}$ ano do Ens. Médio (08/11/2016)

Através da Percepção e Mapeamento de Riscos, próximos a escola os estudantes obtém as técnicas de mapear: observar, selecionar e de classificar, proporcionando ao entendimento da espacialidade dos fenômenos geográficos trabalhados na palestra. A vivência é significativa tanto para criar habilidade de mapear e ler mapas como para a construção do domínio do espaço, para a construção do conhecimento. Tendo como referência PASSINI (2015) O ensino de Geografia e a Cartografia Escolar são indissociáveis e complementares: a primeira é conteúdo e a outra é forma. Não há possibilidade de estudar o espaço sem representá-lo, assim como não podemos representar um espaço vazio de informação.

Tornando cidadãos perceptíveis aos problemas que são encontrados nas paisagens das cidades como: construções em áreas íngremes, a ocupação e o uso do solo desordenado, construções sobre aterros, o corte de taludes, lançamento de lixo e águas nas encostas são fatores que intensificam de movimento de massa e deslizamentos. Possibilita à compreensão do espaço 
geográfico, mostrando que a natureza não está externa ao homem e sim conectada, abordando a relação entre Homem e Meio, atribuindo a concepção de Santos (1998, pág. 96), diz: "Não há produção, que não seja produção de espaço, sendo uma forma de vida do homem".

\section{Considerações Finais}

De fato, a abordagem da Geografia Física nas escolas e de suma importância para tornar os estudantes mais conscientes em relação às dinâmicas da Natureza, através da sala de aula podemos tornar os alunos em verdadeiros disseminadores de informações a respeito dos Riscos Naturais principalmente dos que moram em áreas de risco além de transmitir informações sobre a Defesa Civil de sua cidade.

Levando em consideração a lei 12.608/2012 juntamente com a lei 9.394 Diretrizes e Bases da Educação Nacional, irá facilitar o processo de inclusão da temática de riscos naturais no ensino, por isso, é fundamental a capacitação dos docentes de Geografia na abordagem desse conteúdo além de fortalecer a ideia de Passini (2015) a Cartografia Escolar é a forma, pois a compreensão se dá a partir da leitura do espaço, de modo significativo. Pois é a escola que privilegia a interlocução do mundo e valores que permeiam a sociedade.

Desta forma, pode-se concluir que este trabalho teve como intenção principal estabelecer um projeto que pudesse passar para os alunos toda a informação necessária sobre os riscos naturais por considerarmos este assunto muito importante para toda a sociedade, pois vivemos, interagimos e com isso moldamos o relevo de acordo com a nossa interação com o espaço geográfico e conforme as nossas necessidades. E essa interação precisa ser positiva para que não só vidas possam ser resguardadas mais que também possamos conhecer o meio onde vivemos.

\section{REFERÊNCIAS}

AFONSO, A.E. Geografia Física aplicada ao ensino: educação ambiental e prevenção de riscos naturais na formação de professores. XV SBGFA. Vitória ES. 2013b.

BRASIL. Lei $n^{\circ} 12.608$ de 10 de abril de 2012. Institui a Política Nacional de Proteção e Defesa Civil. Disponível em: <http://www.planalto.gov.br/ccivil_03/_Ato2011-2014/2012/Lei/L12608.htm〉. Acesso em 13 de agosto de 2016.

CEPEDE, UFSC, Centro Universitário de Estudos e Pesquisa Sobre Desastres. Brasil Cresce Seguro: Proposta de Redução de Risco de Desastres nas Escolas- vol. 4 Guia conceitual em Redução de Risco de Desastre, Florianópolis, 2012.

PASSINI, E. Y; PASSINI, R; MALYSZ, S. T. (organizadores). Prática de ensino de geografia e estágio supervisionado- 2ed. - São Paulo: Contexto, 2015. Pág. 143-155.

SANTOS, M. Cap.7: Do Físico ao Humano, do Natural ao Artificial, Geografia Física, Geografia Humana. Metamorfose do espaço habitado, fundamentos teórico e metodológico da geografia. Hucitec. São Paulo, 1998 pág. 95-102. 
